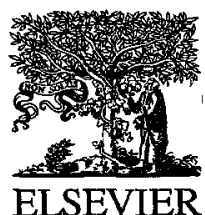

European Journal of Operational Research 99 (1997) 113-125

EUROPEAN

JOURNAL

OF OPERATIONAL

RESEARCH

ELSEVIER

\title{
Financial modelling: Where to go? With an illustration for portfolio management
}

\author{
Jaap Spronk *, Winfried Hallerbach \\ Department of Finance, Erasmus University Rotterdam, P.O. Box 1738, NL-3000 DR Rotterdam, Netherlands
}

Received 1 January 1996; revised 1 July 1996

\begin{abstract}
The definition of Financial Modelling chosen by the EURO working group on financial modelling is "the development and implementation of tools supporting firms, investors, intermediaries, governments and others in their financial-economic decision making, including the validation of the premises behind these tools and the measurement of the effectivity of the use of these tools'. Clearly, in this definition, the decision and its solution is central. Unlike financial modelling in our definition, the theory of finance is not so much concerned with individual decisions, but rather with the effects of the decisions and actions of many individuals on the formation of prices in financial markets. It is therefore no wonder that the assumptions underlying financial theory, which at best describe 'average individuals' and 'average decision situations', are not suited to describe specific individual decision problems. In our view it is the role of financial modelling to support individual decision making, taking account of the peculiarities of the actual case, where possible taking benefit from the results of the financial theory. This philosophy towards financial modelling is illustrated by a framework for portfolio management. (C) 1997 Elsevier Science B.V.
\end{abstract}

Keywords: Financial modelling; Portfolio selection; Multi-attribute/criteria analysis

\section{Introduction}

Over the last few decades the financial arena and the associated disciplines have been changing tremendously. The developments are a good example of a strong mutual influence of both practical and theoretical developments. Examples are the internationalization of capital markets, the emergence of an ever growing variety of new financial products and their markets (e.g. options, futures and swaps) and the ever growing amount of money invested through institutional funds (cf. Bernstein, 1994, for a concise account of these developments).

\footnotetext{
* Corresponding author.
}

In this article we describe and discuss the (potential) contribution of financial modelling to these developments. Since there is a general confusion of tongues, we will first discuss the definition of financial modelling. Often the term 'financial modelling' is used very broadly for any quantitative-analytical description of the financial system or of parts of it, the empirical estimation of relationships and the testing of hypotheses plus the development of quantitative-analytical tools supporting financial-economic decision making. The definition chosen by the EURO working group on financial modelling (being also the one chosen here) is more narrow and more in line with the approach of operational research, applied to financial economic problems. In this view, financial modelling is concerned with the development of 
tools supporting firms, investors, intermediaries, governments etc. in their financial-economic decision making, including the validation of the premises behind these tools and the measurement of the efficacy of these tools. Thus the decision and its solution is central!

The role and position of financial modelling is best described with reference to 'the' theory of finance, by which we mean the constellation of essentially micro-economic theories describing the pricing of both primary and derivative financial assets. This constellation is gradually being extended by paying attention to conflicts of interest between different parties in a contract or relation (agency theory), to the role of information for individual behavior and in pricing (signalling, information economics) and to the role of market structure (theories of market micro-structure and theories of intermediation). When studying decisions by investors or by firms the aim is normally to get insights into the pricing implications of average individual behavior (e.g. the theory of corporate finance). Important building blocks of these theories are utility theory, probability theory and game theory.

Although the theory of finance is essentially micro-economic by nature and thus not per se intended to support non-average decision making, the following straightforward framework for individual decisions is often given: (1) List decision alternatives (which are assumed to be given and fixed). (2) Express each of these alternatives in terms of its associated cash flows and contingent claims in terms of well-defined probability distributions and/or stochastic processes. (3) Use the micro-economic valuation theories to find a (market) price tag for every alternative. (4) Choose the alternative with the highest market value. Whenever this way of modelling decisions is reasonably accurate, success of this approach can be enormous. In the late sixties and the early seventies, many financial-economic problems were approached by operational research techniques (see a.o. the finance textbooks of those days and e.g. Ashford et al. (1988) or McInnes and Carleton (1982) for an overview). A large variety of optimization approaches (but also simulation and heuristics) were proposed as a best effort to find 'the optimal' solution to many different financial-economic decision problems. Thus, at that time, most financial modelling was based on the same set of assumptions as micro-economic financial theory. In the cases where these assumptions are reasonably fulfilled, the success of financial modelling is beyond any doubt (e.g. the later program trading). However, in many financial-economic problems, notably within the firm but also in financial investment problems, the assumptions of micro-economics deviate from reality. Ignoring these deviations may well lead to failures. For many reasons, an actual decision situation may differ from the 'average':

A set of decision alternatives is sometimes given and fixed, but often not. In investment problems for instance it is often not clear at all from which set of opportunities the investment(s) should be selected. Furthermore, the investment decision may be influenced by all kinds of constraints, both explicit and implicit, of which neither the exact location nor their mere existence is clear. Within the firm, the set of capital investment projects is dynamic whereas individual project descriptions may be adapted at a high frequency.

Unfortunately, the information available to describe the decision alternatives concerned is often far less complete than we like. For example in capital investment analysis, we would like to have precise information on future cash flow distributions, but we often have nothing more than some clues with respect to the cash flow generating process. For instance, one may be happy if there is reasonable insight into the main sources of risk and the way the cash flows react to these risk factors. Likewise, in portfolio investment problems, one may assume the existence of return generating distributions and one may even estimate the parameters of these processes and the associated distributions on the basis of historical data, but we simply do not yet exactly know what are the most important forces or attributes driving the future returns of stocks.

Financial theory offers various well elaborated valuation mechanisms. In practical decision situations, both in the area of financial investments and in the area of corporate finance, one may encounter various limitations of these valuation mechanisms. Examples are the case of non-traded assets (for which the standard 'mimicking strategy' is hard if not impossible to apply) and the case of incomplete markets. In addition, many decisions involve more 
objectives than the value maximization criterion assumed by financial theory. Thus even when and if financial theory helps to attach the market price tag to the various decision alternatives, it may still be needed to find a trade-off between these prices and the value of other objectives. Finding such a trade-off is both theoretically and practically a somewhat hazardous task.

If the first three steps can be completed along the lines of the standard recipe, the fourth step, choosing the most preferred solution, is relatively straightforward. And though it may require more or less mathematics to find the optimal solution, the mere concept of optimality is clear. In case the three first steps of the standard recipe can not be followed completely, problems do easily arise. Lack of information, multiple objectives, situations in which more or less complicated games play a role are all potential reasons why an analyst and the decision maker may already be very happy when one or more 'good' solutions can be identified or when all inferior solutions can be eliminated.

This brings us to the three roles of financial modelling:

(1) To get a better idea of the set of alternative decision strategies, i.e. to get insight into the feasibility of different strategies and possibly also to generate new alternatives.

(2) To clarify the relations between decision alternatives and the (potential) results of these alternatives. This may vary from the assessment of probabilities through simulation and econometric techniques to the identification of sources of risk and estimating response parameters.

(3) To help finding a (set of) suitable stream(s) of decision alternatives. Depending on the problem characteristics this may vary from searching feasible solutions, to constructing a partial ordering of the set of alternatives (for instance eliminating all inferior alternatives) to the construction of a complete ordering of the alternatives.

Defined in this way, financial modelling not only involves 'hard core' optimization and econometrics, but also softer techniques like simulation and heuristics, and decision support techniques and problem structuring methods. The emphasis of financial modelling is clearly on instrument building with the ultimate aim that these instruments help to solve problems and thus change reality. This is in contrast with positive theories (like micro-economic theories) having the description of reality as primary purpose. Nevertheless it is important to note that financial modelling can and should benefit from the results of positive theories, be it micro-economic or other. Because the financial modeler should try to clarify (and test the validity of) the premises underlying the tools intended to support the problem solving process, positive theories may also benefit from experiences gained with the modelling process. In other words, experiences with financial modelling should be documented and compared, possibly leading to the discovery of regularities, which then may be used as input for new positive theories or the adaptation of old ones.

In this paper, we have chosen not even to attempt to give an overview of what has been achieved in financial modelling over the last few decades. Given the amount of journal space available, such an overview would be unbalanced, superficial and unfair. Instead, we have chosen to describe and illustrate the philosophy of financial modelling by means of a framework for portfolio management in which results from positive theories can be combined with peculiarities of actual (and thus specific) portfolio management problems. We strongly believe in the importance of promoting this kind of frameworks: not only for portfolio management but also for other financial applications. That is because still too often, financial models are proposed that either neglect important results from positive theories or neglect well-established experiences gained through financial modelling. After deseribing the investment decision process in Section 2, the framework for portfolio management is presented in Section 3. Section 4 describes several ways of using the framework in practice and Section 5 concludes.

\section{The investment decision}

In order to support investment decisions, both the desires (preferences) of the investor and the characteristics of the investment opportunities should be adequately understood and related to each other. Unfortunately, in most models proposed for portfolio management, the real world is replaced by a simpli- 
fied model-world, focusing on the 'average' investor, instead of the particular (typically non-average) investor at hand. However, the assumptions made to describe this average investor are often inadequate and may even be misleading. Consider the meanvariance framework: not only the traditional but also the most popular approach to the investment decision problem. The apparent contribution of Markowitz $(1952,1959)$ and Tobin (1958) is undoubtly that they replace the classic uni-dimensional approach to investment (focusing solely on expected or mean return) by a two-dimensional approach. The formerly undefined notion of risk is formalized by identifying risk with variability of returns in a portfolio context, and operationalized by means of the (co-)variance or standard deviation. The problem, then, is to translate actual decision situation in terms of mean-variance dimensions. However, imposing this two-dimensional world may be too restrictive in practice because the mean-variance framework uses rather strong assumptions on the preferences of the investor and/or the representation of investment alternatives. Variance as a risk measure may miss its link with an investor's preference structure or with the distributions of security and portfolio returns. Information concerning mean and variance is not always sufficient to adequately discriminate between investment alternatives. Still, in many applications, the choice for mean-variance analysis seems almost natural and taken for granted, together with the restrictive nature of the underlying assumptions. In this way, the mean-variance framework becomes a Procrustes bed, chopping off the multi-dimensional aspects that may be perceived by the investor.

In order to elaborate the relationship between the decision context of the investor and the economic environment of the securities, we decompose the investment decision process in the following stages (indicated by capitals in Fig. 1): (1) Security analysis to determine the relevant characteristics (or attributes) of the investment opportunities, (2) portfolio analysis to delineate the set of non-dominated or 'efficient' portfolios, (3) portfolio selection to choose the optimal portfolio from the efficient set, and (4) preference analysis.

In the economic environment box, the securities in the opportunity set are described in terms of various dimensions (attributes) in which securities

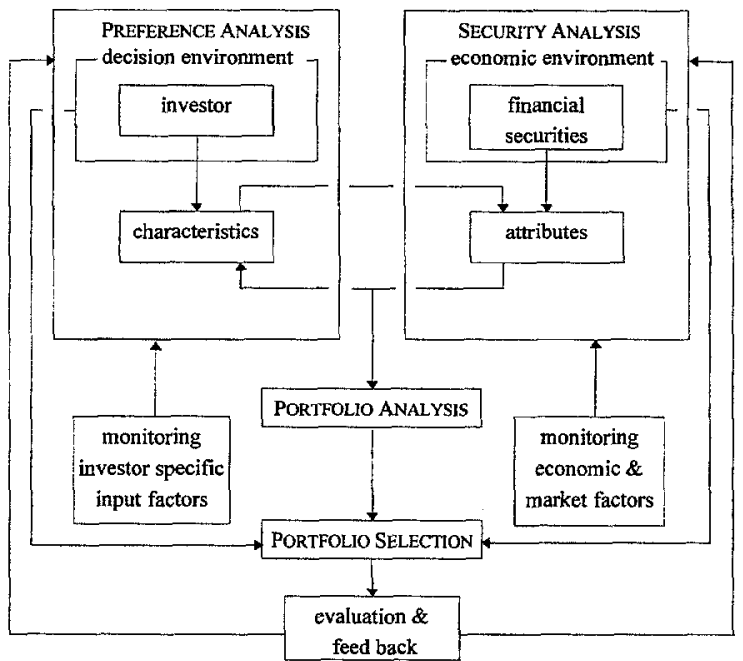

Fig. 1. Global scheme of the investment process.

are likely to differ: expected return, 'risk', maturity, income component, liquidity, manageability, taxability etc. When securities are issued by a firm (like common stocks or corporate bonds) also characteristics of the corresponding firm can be linked to the securities. This view on securities is objective in the sense that it is an 'outsider's view'. Many of these attributes are enumerated in investment text books (see also Section 3).

In the decision environment box, the investor's profile is described, reflecting the decision context and comprising the investment objectives that the investor wishes to attain, the restrictions faced, and his tastes and preferences. Obviously, an investor who has to manage the portfolio of a large institution, who is severely restricted in deciding where and how to invest and who is facing tight limits on the future liquidity of his portfolio, is in quite a different position than a small private investor who is free where and how to invest but who faces high transaction costs and is very limited in his information processing capacity. In more formal terms: the investor's objective function may be multifarious and complex, and may be subject to constraints. Because of specific circumstances, the non-average investor will have to deal with externally imposed constraints. In addition, many investors impose constraints themselves, for instance because they do not like a certain class of assets or because they have only know-how 
with respect to certain asset categories and want to reduce the complexity of the investment problem.

The investor's view on the economic environment in general and on the security characteristics in particular is of a subjective nature and cannot be captured adequately by an 'average' view.

First of all, the investor's profile determines which of the securities' attributes are relevant in the decision-making process. For example, the investor may have a reference portfolio (for example a liability portfolio in case of a pension fund) which calls for an evaluation of security attributes relative to this portfolio. In other cases, there may be restrictions on foreign investments. The investor's profile also determines the degree of relevance of the various characteristics of the securities.

Secondly, it is important to realize that an investor's evaluation of security attributes is subject to his 'bounded rationality'. The human mind is limited both in observing data and processing these data into information, and next in translating this information to an investment decision. The investor's perspective on and perception of the many aspects of a decision situation is not only subjective but (partly as a result) also limited. The investor will not possess perfect insight in the real, 'objective' world and, hence, does not possess 'perfect' information. There may be simply too many variables and choice alternatives to monitor, and an investor is likely to use any circumstantial evidence to form a picture of the world. However, many conventional approaches and in particular the mean-variance approach, presuppose a high-quality knowledge of the joint distribution of investment returns. In reality, the investor will have some information on the future returns of possible returns but this picture will be incomplete. Not only because the possibilities to gather and process information are for every investor limited (be it that these limits differ for different investors) but also because returns depend for a large part on future prices, rates and other variables that are in principle unpredictable (e.g. because they are generated in efficient markets).

Given the relevant securities' attributes as perceived by the investor, the portfolio composition stage comprises the combination of securities into a portfolio that exhibits a constellation of attributes according to the investor's feelings or preferences. The preference structure of the investor is normally more complicated than the relatively simple utility functions assumed within the mean-variance framework. The investor may well have other objectives than financial value maximization alone. For instance, he may want to achieve a stable growth rate of the portfolio's value or a minimum pay-out ratio. Here again, however, bounded rationality will leave its traces. It would be utopian to suggest that the investor can list all available alternatives, compare them and choose the best or optimal alternative. The decision process will instead be characterized by a step-by-step search for an alternative that satisfies his requirements. Optimizing behavior is then replaced by satisfying behavior. Contributions to investment decision problems then do not entail the specification of 'optimal' decision rules, but the design of systematic search procedures that help the investor scan the feasible choice alternatives. Note in this respect that within the mean-variance framework it is not possible to 'play' with the location of self-imposed constraints (although many investors might be willing to change a locally-imposed constraint, for example when that would considerably increase expected return).

As portfolio investment is an ongoing process, the investor's profile as well as the securities profiles need to be monitored continuously. Any relevant change is incorporated in the portfolio composition process. In addition, information about the performance of the investment portfolio is fed back and the investment cycle starts again.

We conclude that it is important that the interrelationship between the decision context and the economic environment is explicitly recognized in framing financial decisions. Given the strong interdependence between investor's and securities' characteristics, the evaluation of security characteristics must take place relative to an investor's own unique circumstances. It is precisely this notion that underlies the approach we propose in Section 3.

\section{A general framework}

The general framework for molding the investment decision process can be labelled as a 'multi-attribute approach to portfolio selection'. The notion that the portfolio investment decision for individual 
investors calls for a multi-attribute approach dates back to Smith $(1974$, p. 53). Of course, there are many more examples of molding the portfolio selection problem in terms of multi-criteria decision making (see Section 3.2). In comparison with the general framework described below, most (if not all) of these approaches are at best only partial. For instance, some approaches (like Arthur and Ghandforoush, 1987) fail to give room for the inherent complexity of the decision procedure given the investor's specific decision context. Other approaches (like O'Leary and O'Leary, 1987) concentrate on the beauties of a particular multiple criteria decision method, without doing full justice to the decision context and to the results and principles of financial economic theory.

The general framework proposed here consists of two stages: the formulation of a multi-attribute representation of securities and the selection of a portfolio. The multi-attribute representation of securities assumes that an investor can demarcate a set of security attributes that he considers relevant. For the investor, a financial security then represents a basket of, say, $k$ attributes and can fully be characterized by a $k$-tuple of attribute values. In this view, when buying a security, an investor is actually buying an exposure to various attributes. The issue of multi-attribute portfolio selection is to balance the attributes of the individual securities on the portfolio level. That is, given the security attributes and the investor's profile (personal context), the attributes of his portfolio must be fashioned in a way that suits his particular circumstances and preferences best. The two stages will be discussed in more detail below.

\subsection{Multi-attribute representation of securities}

In representating securities, we distinguish between attributes that are directly return related (comprising (explicit) expected return and risk measures) and those that are indirectly return related (which are more loosely related to risk and return).

\subsubsection{Directly return-related attributes}

Most academic work assumes that securities can fully be characterized by the joint distribution of their returns. Any probability distribution can fully be described by means of its locus and its shape. An obvious attribute candidate then is the 'expected return' on a security, which refers to the location parameter of the return distribution.

The risk attached to a security's return is directly related to the shape of its distribution. The shape of a distribution can be described either by its shape parameters or by statistical moments. From the view of portfolio formation, not the (marginal) distributions of the securities must be represented, but their joint distribution. When relying on either shape parameters or moments as risk attributes, one faces three problems, each related to one of the stages in the investment decision process as described in the former section ${ }^{1}$. In the stage of security analysis, an 'information problem' arises because all of the interactions between the security returns on the level of the relevant parameters or moments have to be accounted for. In the stage of portfolio analysis, a 'combination problem' arises because the relevant security attributes must be processed and aggregated in order to obtain portfolio attributes. Finally, there is a 'criteria problem': in order to incorporate the probabilistic information in the decision process one must specify both the investor's tastes with respect to each of these attributes and their relative importance. It follows that the risk dimension is truly problematic in its complexity. The ambiguity of the aspect of perceived risk is an additional problem. Indeed, the very lack of adequate risk definitions may be symptomatic for the multi-dimensional nature of risk.

In order to tackle the information problem and the combination problem, we suggest a multiple factor approach for extracting risk measures. The key as-

\footnotetext{
'Additional problems are of a pure statistical nature. When relying on shape parameters one must explicitly assume that the security returns are generated by some specific distribution. Furthermore, it is required that the distribution belongs to the stable class, i.e. the set of distributions that are closed under addition. Otherwise, portfolio returns would obey distributions different from those of the securities and hence possess different shape characteristics. Alternatively, one could try to describe the distributions' shapes by means of their moments. Unfortunately, there is no one-to-one relationship between the shape of a distribution and its moments. For example, zero odd-order moments are a necessary and not a sufficient condition for distribution symmetry. Cf. Barnes et al. (1978) for references on this point.
} 
sumption is that the returns of the securities in the opportunity set are influenced or generated by a series of identifiable economic variables or 'factors' (cf. Chen et al., 1986, and Berry et al., 1988). Each of these factors represents a dimension of the economic environment in which the security returns are generated. Depending on the specific circumstances (the profile) of the investor, a specific set of factors may be relevant. The relationship between a security's return and changes in these factors is described by a response coefficient or factor sensitivity. By means of these sensitivities, the joint distribution of security returns is linked to the joint distribution of factor changes. In this interpretation, the sensitivity coefficients can serve as risk measures. Considering factor sensitivities as relevant security attributes, we arrive at a multi-factor representation of security returns. As the variability of returns is linked to the variability in various identifiable economic variables, investment risk becomes an intuitive and multi-dimensional concept. In the context of this risk concept, the investor is assumed to have some idea of the securities' factor sensitivities.

The use of factor models permits replacing return variance as a uni-dimensional risk measure by multi-dimensional risk measures. These measures provide more insight in the nature of risk than a uni-dimensional, 'aggregate' risk measure. In addition to this decision-theoretic argument there is a statistical argument: the use of factor models for simplifying the representation of joint return distributions is indispensable for enhancing the computational tractability and practical applicability of risk measures (cf. Hallerbach (1994) for an in-depth treatment).

\subsubsection{Indirect return related attributes}

Experiences from practice show that not all relevant information seems to be captured by explicit return and risk attributes. To fill this gap, we leave room for additional attributes that may be incorporated at the investor's discretion. These other attributes may be considered of general relevance in practice, but may also be relevant because of idiosyncrasies in the investor's personal decision context. In the latter case, the incorporation of additional attributes can be motivated from either the specific tastes and desires (goals) of the investor, from spe- cific investment constraints he faces, or from distinctive characteristics of the investment alternatives. In short, the investor can simply indicate that there exist various other attributes with which he can discriminate between the attractiveness of various securities. For example, because of the investor's tax situation, the taxability of the portfolio components may be a relevant attribute (in which respect the portfolio's dividend yield may be important). In terms of 'liquidity' or the flexibility to revise the portfolio's composition, the marketability of the component securities may be relevant. Because of some method of performance measurement, the position with respect to some benchmark portfolio may be relevant, and so on. In addition, the investor may adhere to the notion that not all future events can be reduced to probability distributions, not even when the latter are of a subjective nature. This also implies that attributes may be considered in addition to explicit elements of return and explicit components of risk. We must seriously consider the possibility that some of these 'other' attributes act in fact as proxies for (components of) expected return and risk.

One way to concretisize the potential relevance of various stock attributes is to look at the variables that appear in schemes for fundamental company analyses and industry or sector analyses ${ }^{2}$. A more direct way to detect dimensions in which the appraisal of securities (stocks) may differ is to look at the security analyses as conducted by investors in practice. The early study by Baker and Haslem (1974), for example, concludes that the investor's investment analysis of common stock appears to be a multi-dimensional process. In particular, they find that investors greatly differ in their perceptions of the importance of dividends, future (sales and earnings) growth expectations and financial stability.

With some imagination, the attributes stemming from sources as mentioned above may be labelled 'demand pull'. The data are generally available or can be obtained without many efforts, and investors may use some or all of these data in some way or another. Although the specification of relevant attributes is on the discretion of the investor himself,

\footnotetext{
${ }^{2}$ For these schemes, we refer to Ross et al. (1993, Ch.2) or Reilly (1994, Chs. 17 and 18).
} 
we can draw a clearer picture of the importance of indirect return related attributes by referring to attributes whose relevance is acknowledged through empirical study. Many of these 'validated' attributes are used and advertized by professional investors and may be marked 'supply push' ${ }^{3}$.

Many attributes are considered important, not only from a practical point of view, but also from an academic point of view because they represent 'anomalies' 4 . For common stocks, 'firm size' is a long-time notorious variable. Other examples are price ratios as indicators for fundamental firm value, like earnings/price, book/price (book value of common equity per share divided by market price per share), cash flow/price, sales/price and dividend/price. In the context of 'value investing' there is great renewed interest in these long time familiar attributes ${ }^{5}$.

In the view of (positive) financial theory, an attribute's ability to contribute to the explanation of cross-sectional return differences appears to be a convincing criterion for the selection of relevant attributes. However, an attribute will only carry a significant premium when it is 'priced' in the market. However, a non-average investor can face a set of investment opportunities that is different from the market (i.e. the average investor). Hence this investor is only interested in the relevance of this attribute in his opportunity set. Furthermore, partly connected to the former argument, the reward that an

\footnotetext{
${ }^{3}$ Some examples are Goldman, Sachs and Co. (Jones, 1990; Jones et al., 1990), Salomon Brothers (Sorensen et al., 1989; Bower and Bower, 1991) and BARRA International (Arnott et al., 1989; Fogler, 1990). Note that we do not suggest that for this reason any investor should consider these attributes. Rather, the implication applies in reverse: because investors in general show a preference (or an aversion) towards some attribute, this can have a negative (positive) effect on the return on a security that has much' of this attribute, and vice versa.

${ }^{4}$ An attribute is an anomaly with respect to an asset pricing theory when that attribute possesses power to explain cross-sectional variation in expected returns in addition to the risk measures as specified by the pricing model at hand. An attribute is an anomaly with respect to the efficient market hypothesis when it can be used to forecast future returns. Detailed overviews are provided by Fama (1991) and Hawawini and Keim (1995).

${ }^{5}$ See for example Fama and French $(1992,1993)$ and Lakonishok et al. (1994).
}

investor attaches to the exposure to an attribute (a 'subjective' premium) may well be different from the premium that the market as a whole attaches to that attribute (the 'objective' premium). This leads us back to the starting point that the selection of attributes depends on the personal circumstances of the investor, as summarized in his profile. In brief, there exist security attributes that are relevant in practice, despite the official view of financial theory.

As a whole, the multi-attribute representation of securities comprises a detailed and investor-specific security analysis. Preference information is used to demarcate the set of $k$ attributes that an investor considers important. As a result, each of the securities in the opportunity set can be adequately characterized by the values that the respective $k$ attributes take on. The selection of relevant attributes is no 'once and for all' activity. The investor's decision context and the securities' economic environment may change over time and may become 'better understood' because of 'learning effects'. As a result, the set of relevant attributes may change over time.

\subsection{Multi-attribute portfolio selection}

As the attributes are evaluated in a portfolio context, the first issue in portfolio analysis, then, is aggregating the security attribute scores according to their investment fractions. As most of the potential attributes considered so far are linear, this will not pose any difficulty ${ }^{6}$. The second issue is to confront the multi-attribute representation of securities with the investor's preference structure in order to evaluate feasible portfolios and to select a portfolio. We first discuss investor tastes and preferences about securities, expressed in scores on attributes. Next, we summarize standard approaches that are currently employed in investment practice. Finally, we present

\footnotetext{
${ }^{6}$ Note that the direct return related attributes (expected return and factor sensitivities) are linear. However, the indirect return related attributes can cause some problems. For example, individual securities' price/earnings ratios must be aggregated in harmonic form in order to obtain a portfolio's price/earnings ratio. It is then simpler to consider the securities earnings/price ratios, which can be aggregated in a linear fashion to a portfolio earnings/price ratio.
} 
an alternative approach that does justice to the flexibility allowed in the security analysis and preference analysis.

\subsubsection{Choosing between attribute exposures}

The step from securities to their representation in terms of attribute scores can be justified by referring to consumer theory, where 'characteristics models' have been developed for describing consumer behavior. In this respect we especially note Lancaster (1966, p. 133), whose contribution is "breaking away from the traditional approach that goods are the direct objects of utility and, instead, supposing that it is the properties or characteristics of the goods from which utility is derived", 7. These implied characteristics models opened the way for a theory of multi-attribute choice.

Transposed to the investment decision, we can assume that investors buy securities for the attributes they offer and that different securities are essentially different packages of attributes. This implies that investors choose between security attribute exposures instead of between the uni-dimensional securities or their returns. Hence, an investor's preference functional is directly specified in the multi-dimensional terms of relevant security attributes ${ }^{8}$. For an investor, a financial security then represents a basket of, say, $k$ attributes and can fully be characterized by a $k$-tuple with scores or values that the attributes take on. In an investor's view, when buying a security, he is actually buying an exposure to various attributes. Hence, we can specify a mapping of the securities in the space spanned by the attributes:

security $i \rightarrow\left\{a_{i 1}, a_{i 2}, \ldots, a_{i j}, \ldots, a_{i k}\right\}, i \in N$

where $a_{i j}$ is the value that attribute $j$ takes for security $i$. Likewise, when composing a portfolio,

\footnotetext{
${ }^{7}$ For a discussion and review of characteristics models, we refer to Deaton and Muellbauer (1980).

${ }^{8}$ Consumer theory considers decision making under certainty. Because we are dealing with situations of uncertainty or risk, we assume that some subset of attributes captures the risk aspects, so that attitudes towards risk can be reflected in the preference functional.
}

the investor is actually composing an appropriate portfolio exposure to the various attributes:

portfolio $p \rightarrow\left\{a_{p 1}, a_{p 2}, \ldots, a_{p j}, \ldots, a_{p k}\right\}$

For a given portfolio, its exposure to a certain attribute can be calculated as a weighted average of the attribute exposures of the individual securities contained in this portfolio. The fractions invested in each of these securities can thus be treated as instrumental variables. Therefore, the attribute exposures can be seen as goal variables which are linear in the portfolio holdings. Often, the investor will try to either minimize or maximize each of these goal variables. Alternatively, the investor may strive to attain a target level or desired score on some attribute(s). Depending on the investor's insights and preferences, the relative importance of each of these goals may vary. Generally, no portfolio can be found for which each of the goal variables reaches its optimal value or for which all criteria are met. As a consequence, the investor has to evaluate the tradeoffs between the various goal variables.

\subsubsection{Alternative selection procedures}

There are several routes leading to the selection of a portfolio, depending on the amount of information available on the investor's preference structure.

Assuming a large amount of preference information, the traditional utility framework could be extended to a multi-dimensional context by casting a utility function in terms of multiple portfolio attributes. Consequently, the mean-variance preference functional $Z\left(E_{p}, \sigma_{p}^{2}\right)$ is replaced by a "Lancaster (1966)-type' of function $Z\left(a_{p 1}, \ldots, a_{p k}\right)$. In that case, an explicit optimization problem can be formulated and solved. Unfortunately, the complexity of specifying a multi-attribute preference functional is enormous and not likely to be overcome in practice. In multi-attribute utility theory, this complexity is reduced by assuming (strong) separability of the preferences. When this assumption is satisfied, a series of uni-dimensional (i.e. single attribute) utility functions can be assessed, whereafter these component functions are combined (in a linear, multiplicative or other fashion), using information about attribute trade-offs. In this way, the exposures are evaluated attribute by attribute and then combined to obtain an overall measure of desirability. Still, this 
places a heavy information burden on the investor. The problem here is to ex ante specify the uni-dimensional preferences for each of the attributes as well as the overall preference functional that incorporates the evaluation of a combination of attribute exposures and their trade-offs.

Another route is to cast the multi-dimensional preference functional in the form of a (linear) programming model. One way is to maximize the portfolio's exposure to one attribute (expected return, e.g.) subject to restrictions on the other attribute scores ${ }^{9}$. The problem with such a specification is that it is intrinsically uni-dimensional: only one attribute is optimized, while the other attributes only serve as constraints. Another way to extend the linear programming formulation to a multi-dimensional context is to use a weighted average of the various attributes as the objective function ${ }^{10}$. A linear programming formulation like this can only be employed when the trade-offs between the attributes can be specified properly.

In formulating priorities and targets with respect to attributes and attribute exposures, goal programming offers more flexibility. The applicability of multiple goal programming to the portfolio problem was recognized in an early stage. In the $\left(E, \sigma^{2}\right)$ context, we have Lee (1972); Lee and Lerro (1973); Kumar et al. (1978); Lee and Chesser (1980); Spronk (1981) and O'Leary and O'Leary (1987). Aside from expected return and risk, some indirect return related attributes (notably dividend yield) are specified, but a truly multi-attribute representation is not pursued. In all studies but the last, risk is accounted for by the linear approximation of Sharpe (1967), of portfolio return variance on the basis of the single index model, or simply by a target for a market index model beta. Of course, the number of attributes could easily be extended towards multi-dimensional risk measures and various additional indirect return related attributes. Multiple goal programming indeed has some attractive properties. It shows a close correspondence with decision making in practice, the goals are formulated as aspiration levels and there is always a solution for a well-defined problem (with a

\footnotetext{
${ }^{9}$ Cf. the portfolio optimizer of Sorensen and Thum (1992).

${ }^{10}$ One example is Arthur and Ghandforoush (1987).
}

non-empty feasible region), even if some goals are conflicting. An important drawback of multiple goal programming, still, is its need for fairly detailed a priori information on the decision-maker's preferences.

Interactive programming methods, in contrast, neither require an explicit representation or specification of the decision-maker's preference function nor an explicit quantitative representation of the tradeoffs among conflicting goals. By its nature, an interactive procedure progresses by seeking this information from the investor, removing the need for explicitizing the preference structure. For the investment problem as sketched in this study, we propose interactive multiple goal programming (henceforth IMGP), as developed by Spronk (1981). In this procedure, the investor reduces the set of alternatives interactively and systematically, thus conditioning the quality of the remaining portfolios. The investor has several options. He can continue until the remaining set of feasible portfolios becomes very small. Another possibility is to select a suitable portfolio from the set of portfolios satisfying the minimum requirements. In this respect, IMGP produces at each iteration a set of non-dominated portfolios. Finally, a set of feasible portfolios satisfying the minimum conditions on the goal values can be subjected to a second analysis by the investor. In his decision context, the investor may wish (or need) some elbow-room, thus requiring more than just one portfolio. The procedure then offers adequate flexibility to incorporate other, hard to quantify, criteria into the decision making process. IMGP incorporates all the advantages of 'traditional' goal programming, while circumventing the unnecessary burden of obtaining a 'complete' picture of the investor's preference pattern. In our opinion, this approach offers the desired degree of flexibility to be fruitfully applied to the multi-attribute portfolio selection problem. By tuning the attribute exposures, a specific portfolio profile can be obtained that matches the investor's profile. The stages of portfolio analysis and portfolio selection are no longer treated separately but are integrated. The interactive method then is no optimizer, but can better be described as a 'combinizer': it allows systematic scanning of the set of feasible portfolios and the selection of an optimal portfolio via an interactive process. In the interactive decision 
process, a learning process is embedded. By scanning the feasible portfolios, the investor first gets a feeling for the trade-offs that in the opportunity set exist between the exposures to the various attributes. Second, the investor can shape and adjust his preferences when confronted with the trade-offs between the attributes. It is in no way required that the investor performs the interactive process only once. He can explore the opportunity set in all dimensions, and is even advised to do so in order to get insight into the properties of the opportunity set at hand. Since the interactive procedure is path-independent, no desirable (feasible) alternatives can be missed, only insight can be gained.

\section{Different ways of using the framework}

A distinctive feature of the multi-attribute approach to portfolio selection is that it can accommodate an investor's specific decision context, as summarized by his goals, tastes and restrictions. The proposed framework offers ample flexibility and can be used in many different ways. In particular, the multi-dimensional risk concept that emerges from multi-factor models provides opportunities for a sophisticated management of investment risks ${ }^{11}$. Applications range from mere portfolio analysis to the actual selection of an optimal portfolio, from defensive to aggressive strategies and from passive to active strategies. A portfolio strategy now entails the choice of an appropriate pattern of factor sensitivities or, in general, of attribute scores.

A general application of the framework is "scanning' a portfolio's profile. A scan entails an inventarization of its exposures to the attributes considered relevant. By determining the sensitivities for various factors, the systematic risk profile of a given portfolio can be summarized in terms of its economic factor exposures. As a portfolio is not likely to be perfectly diversified with respect to the economic

\footnotetext{
${ }^{11}$ We distinguish between an 'Arbitrage Pricing Theory approach' and a 'multi-factor model approach'. The former is restricted to manipulating the exposure to market priced risk factors, whereas the latter considers both priced and non-priced risks.
}

risk factors, the factor risk profile must be complemented with information about non-factor risks. This can be done by incorporating a residual market factor, which represents the influences of both omitted economic factors and 'market mood' (psychological) factors on a portfolio's return behavior (Berry et al., 1988). For large portfolios, most of the return variability can be attributed to the economic factors and the residual market factor. The scores on the indirect return related attributes complete the portfolio profile. Scanning can be supplemented by conducting sensitivity analyses, for example on the basis of economic scenarios. A scenario then entails a specific constellation of potential factor realizations. Given a portfolio's risk profile, the exposure to some factor can be combined with a hypothesized change in that factor. This yields a 'ceteris paribus' portfolio return that can be attributed to the factor.

Scanning implies a passive use of the framework. An active and aggressive portfolio strategy is 'tilting'. Starting from a 'normal' portfolio (i.e. a benchmark or target portfolio which is considered suitable over a longer time horizon; Kritzman, 1987), an investor may wish to deviate from this portfolio in a controlled way. By tuning the sensitivity coefficients, a specific risk profile of the investment portfolio can be chosen. For example, when the investor forecasts a decrease in the interest rate, he can decrease (in algebraic sense) the portfolio's interest rate sensitivity, while controlling its exposure to other factors. In specifying this 'factor tilt', 'factor play' or 'factor bet', interest rate risk is considered as an opportunity and the investor intends to earn excess returns from this source. A crucial condition for adopting this strategy is that the investor has superior forecasting abilities, in order to predict factor movements that are unexpected to other investors ${ }^{12}$. Tilting can be extended to the exposures to other attributes. As set out Section 3.1, there are indications that some attributes possess predictive abilities for future excess returns. While controlling risk exposures and other attribute scores, an investor could then strive to tilt his portfolio to high dividend

\footnotetext{
${ }^{12}$ The application of the active strategy is pointed out by Berry et al. (1988), Sorensen et al. (1989) and Sorensen and Thum (1992), among others.
} 
yield, low price/earnings ratio, low price/book ratio or small capitalization (see Sorensen and Thum, 1992, e.g.).

In contrast to aggressive strategies, defensive strategies do not require factor forecasts. Here, risk is considered as a threat, not as an opportunity and defensive strategies intend to shield a portfolio's return from undesired factor influences. A passive defensive strategy is 'risk sterilization': a portfolio's composition is shifted in order to mitigate or negate factor exposures that are considered to be excessive. An active defensive strategy is hedging: a portfolio's risk exposure is structured in accordance with the economic profile of the investor, which encompasses the pattern of his expenditures, his other sources of income and the economic conditions he will face. In this way, the choice of an appropriate pattern of risk exposures is explicitly linked to the uses to which the income generated by the portfolio is to be put (see Roll and Ross, 1984). In general terms, a hedging strategy takes the form of 'matching'. Given the investor's liabilities as specified by his economic profile, the risk exposure of the assets (i.e. investment portfolio) is manipulated to absorb the risks that are incurred on the liability side. By pairwise equating the factor sensitivities of assets and liabilities, one could strive to achieve a certain degree of hedging. This form of risk management is especially relevant for institutional investors like pension funds.

The multi-factor context signifies as a conceptual framework for an integrated approach to risk management. Especially for hedging purposes, the analysis of the characteristics of liabilities and assets (investment portfolios) in one unified, consistent framework is indispensable.

\section{Conclusions}

In our view, the central role of financial modelling is to support individual decision making, taking account of the peculiarities of the actual problem at hand, where possible taking benefit from the results of financial theory. This encompasses (1) investigating the set of alternative decision strategies, (2) clarifying the relations between decision alternatives and the (potential) results of these alternatives, and (3) searching for a (set of) suitable stream(s) of decision alternatives.
Our view on financial modelling is illustrated with a general framework for portfolio management that can serve as an aid in making investment decisions. The framework is decision oriented. It is very general in the sense that it can accommodate any type of investor. The framework is also very specific because it gives room to different settings of the portfolio management problem. It tries to use all available information without requesting the investor to formulate ex ante a complete expected return-covariance structure of future returns. Finally, it leaves room for a much broader class of preference structures than allowed within the Markowitz approach. Although the presented framework is suitable for a broad range of investors, it does frame the portfolio management process in a way which requires a certain amount of discipline on the side of the investor. From another perspective, the framework offers the investor systematic guidance in the search for a portfolio that meets his investment goals as close as possible while opening the possibility to systematically learn from past experiences.

\section{References}

Arnott, R.D., Kelso, C.M., Kiscadden, S. and Macedo, R. (1989), "Forecasting factor returns: An intriguing possibility", The Journal of Portfolio Management, Fall, 28-35.

Arthur, J.L. and Ghandforoush, P. (1987), "Subjectivity and portfolio optimization, in: K.D. Lawrence, J.B. Guerard and G.R. Reeves (eds), Advances in Mathematical Programming and Financial Planning, Vol. 1, JAI Press, Greenwich, CT, 171-186.

Ashford, R.W., Berry, R.H. and Dyson, R.G. (1988), "Operational research and financial management", EJOR 36, 143152.

Baker, H.K. and Haslem, J.A. (1974), "Toward the development of client-specified valuation models", The Journal of Finance 29/4, Sept., 1255-1263.

Barnes, J.W., Zinn, C.D. and Eldred, B.S. (1978), "A methodology for obtaining the probability density function of the present worth of probabilistic cash flow profiles", AIIE Transactions 10/3, Sept., 226-236.

Bernstein, P. (1994), Capital Ideas, Basic Books, New York.

Berry, M.A., Burmeister, E. and McElroy, M.B. (1988), "Sorting out risks using known APT factors", Financial Analysts Journal March-April, 29-42.

Bower, D.H. and Bower, R.S. (1991), "The Salomon Brothers electric utility model: Still a challenge to market efficiency", Financial Analysts Journal March-April, 45- 54. 
Chen, N.-F., Roll, R. and Ross, S.A. (1986), "Economic forces and the stock market", The Journal of Business 59/3, July, 383-403.

Deaton, A. and Muellbauer, J. (1980), Economics and Consumer Behavior, Cambridge University Press, Cambridge, UK.

Fama, E.F., (1991), "Efficient capital markets: Il", The Journal of Finance 46/5, Dec., 1575-1617.

Fama, E.F. and French, K.R. (1992), "The cross-section of expected stock returns", The Journal of Finance $47 / 2$, June, 427-465.

Fama, E.F. and French, K.R. (1993), "Common risk factors in the returns on stocks and bonds", Journal of Financial Economics 33, 3-56.

Fogler, H.R. (1990), " Common stock management in the 1990s", The Journal of Portfolio Management Winter, 26-35.

Hallerbach, W.G. (1994), "Multi-attribute portfolio selection: A conceptual framework", Doctoral Dissertation, Erasmus University Rotterdam.

Hawawini, G. and Keim, D.B. (1995), "On the predictability of common stock returns: World-wide evidence", in: R.A. Jarrow, V. Maksimovich and W.T. Ziemba (eds), Finance, Handbooks in Operations Research and Management Science, North-Holland, Amsterdam.

Jones, R.C., (1990), "Designing factor models for different types of stock: What's good for the goose ain't always good for the gander", Financial Analysts Journal March-April, 25-30, 50.

Jones, R.C., Kohn, L.A. and Melnikoff, M. (1990), " Quantitative equity investment strategies, Goldman Sachs asset management", Goldman, Sachs and Co., New York, NY, July.

Kritzman, M., (1987), "How to build a normal portfolio in three easy steps", The Journal of Portfolio Management Summer, 21-23.

Kumar, P.C., Philipatos, G.C. and Ezell, J.R. (1978), “Goal programming and the selection of portfolios by dual purpose funds", The Journal of Finance 33/1, March, 303-310.

Lakonishok, J., Schleifer, A. and Vishny, R.W. (1994), "Contrarian investment, extra polation, and risk", The Journal of Finance 49/5, Dec, 1541- 1578.

Lancaster, K.J. (1966), "A new approach to consumer theory”, Journal of Political Economy 74, April, 132-157.

Lee, S.M. (1972), "Goal Programming for Decision Analysis, Auerbach, Philadelphia.
Lee, S.M. and Chesser, D.L. (1980), "Goal programming for portfolio selection", The Journal of Portfolio Management Spring, 22-26.

Lee, S.M. and Lerro, A.J. (1973), "Optimizing the portfolio selection for mutual funds", The Journal of Finance $28 / 5$, Dec., 1087-1101.

Markowitz, H.M. (1952), "Portfolio selection", The Journal of Finance 7/1, March, 77-91.

Markowitz, H.M. (1959), Portfolio Selection: Efficient Diversification of Investments, John Wiley, New York.

McInnes, J.M. and Carleton, W.J. (1982), "Theory, models and implementation in financial management", Management Science 28/9, 957-978.

O'Leary, J.H. and O'Leary, D.E. (1987), “A multiple goal approach to the choice of pension fund management", in: K.D. Lawrence, J.B. Guerard and G.R. Reeves (eds), Advances in Mathematical Programming and Financial Planning, Vol. 1, JAI Press, Greenwich, CT, 187-195.

Reilly, F.K. (1994), Investment Analysis and Portfolio Management, Dryden Press, Fort Worth, TX.

Roll, R. and Ross, S.A. (1984), "The arbitrage pricing theory approach to strategic portfolio planning', Financial Analysts Journal May-June, 14-26.

Ross, S.A., Westerfield, R.W. and Jaffe, J.F. (1993), Corporate Finance, Irwin, Homewood, IL.

Sharpe, W.F. (1967), "A linear programming algorithm for mutual fund portfolio selection", Management Science 13/7, 499-510.

Smith, K.V. (1974), "The major asset mix problem of the individual investor", Journal of Contemporary Business Winter, $49-62$.

Sorensen, E.H., Mezrich, J.J. and Thum, C.Y. (1989), "The Salomon Brothers U.S. stock risk attribute model", Salomon Brothers Inc., New York NY, Oct. 17

Sorensen, E.H. and Thum, C.Y. (1992), "The use and misuse of value investing", Financial Analysts Journal March-April, $51-58$.

Spronk, J. (1981), Interactive Multiple Goal Programming: Applications to Financial Planning, Martinus Nijhoff, Boston.

Tobin, J. (1958), "Liquidity preference as behavior towards risk", Review of Economic Studies 25, 65-86 